This is an Accepted Manuscript of an article published by Taylor \& Francis in Disability and Rehabilitation on 08/02/2020, available online: https://www.tandfonline.com/doi/full/10.1080/09638288.2020.1722263. 


\title{
From recovery to regaining control of life- the perspectives of people with stroke, their carers and health professionals
}

\begin{abstract}
Aim: To understand how people with stroke and carers adapt over time, and how health professionals support transition to home. Method: A multi-perspective, prospective, qualitative, longitudinal study was conducted using in-depth semistructured interviews one and six months after inpatient discharge. Twenty-four participants (eight triads, including people with stroke, carers and health professionals) were included. Thematic and narrative analysis facilitated identification of cross-cutting themes according to individual trajectories poststroke. Findings: A major theme: "regaining control of life" suggested a shift in perspective after six months at home. Four sub-themes help to understand the triads' perspectives over time: i) importance of team involvement; ii) differences in perceived roles within the triad; iii) differences in expectations and collaboration within the triad and iv) planning a different future. People who were involved in supporting adaptation and rehabilitation processes were reported differently between triads and over time, showing the complexity of interrelations. A reduction in professional involvement was matched by changes in participants' goals and expectations. Conclusion: Findings suggest the importance of a dyadic perspective and a gradual increase in people with stroke and carers' active engagement. Professionals' approach throughout rehabilitation should be modified according to people with stroke and carers' changing needs and expectations.
\end{abstract}

Keywords: stroke; caregivers; family; adaptation, psychological; goals; qualitative research

\section{Introduction}

Stroke continues to be one of the most common causes of complex disability in adults worldwide $(1,2)$ and provides a unique set of challenges for both the person with stroke and their family. Due to the complexity of the impact and recovery, stroke affects families more broadly than many other chronic diseases (3). The impact of stroke is often 
characterised by its suddenness, giving no time for both people with stroke and carers to prepare for changes in their lives, and the associated uncertainty, fear and anxiety (4-8). The impact on families may result in a transformation of roles and relationships $(9,10)$. The strategies each finds to manage the effect of stroke in their routines may be different, but not necessarily independent of the coping and adaptation process of other family members and they may help each other managing the demands provoked by the stroke. Living together in a relationship influences how daily tasks are done, managed and divided between family members $(9,10)$. Previous studies from a family or couple's perspectives underline the role of interdependence between the person who has had a stroke and the partner for recovery and well being (9-14). This indicates that the experience of stroke should not be seen as an individual phenomenon. Although these previous findings underpin the importance of considering the dyad - the person with stroke and the carer - as a unit, most studies have tended to emphasise the experiences of the person with stroke, whilst the carers' role and perspective are not always clear, suggesting that the impact of stroke on the family as a whole is an area for more research.

Findings have also demonstrated the importance of professional support to helps individuals and families adapt after stroke, highlighting the ability of health professionals to understand people's needs and be flexible in their approach according to their priorities $(12,15)$. However, triad combinations including people with stroke, carers and health professionals have been investigated far less often and, commonly, give limited insight from the carers' perspective and roles. Most previous studies have focused on analysing the interaction between the person who had experienced a stroke and the health professional (16-19). Few have also included the carers' perspectives on their involvement in the rehabilitation process (17-20). Placing the person with stroke at the centre of rehabilitation may give only one description of the problem and professionals 
are more likely to "miss the point" (21). Considering the needs of people with stroke and their family, the interrelation within the triad could help inform ways to evaluate and facilitate the coping and adaptation processes at home after discharge from regular rehabilitation.

In addition, longitudinal studies suggest that the path of adaptation continues to present challenges to people with stroke and their carers/ families over time (22-24). Differences in perspective within dyads seem to become more pronounced over time, with carers being more likely to continue to focus on people post stroke' difficulties than on themselves (22). Different dyads may also adapt differently, which may have consequences for how daily life is spent after stroke (15). Moreover, differences in perspective between the person post stroke/carer and health professionals have been reported $(19,25)$. However, the available literature is limited on their interrelations and implications of these changing relationships over time, as well as the role of health professionals to support adaptation to life after stroke.

In Portugal stroke remains the main cause of death and disability for elderly people $(26,27)$. It is estimated that approximately $40-45 \%$ of Portuguese stroke survivors may present with mild to moderate neurological impairment and around $20 \%$ may have a severe degree of disability $(28,29)$. In addition, most people who have had a stroke are discharged to their homes, which emphasises the sizeable role played by family members. However, published research exploring the adaptation process from the perspective of the Portuguese people with stroke and carers is almost non-existent. Previous research has been focused mainly on the perspective of carers (30) or on the experience of stroke reported five decades ago (31). Additionally, how Portuguese health professionals may support their transition to home and adaptation is unknown. 
Therefore, determined by the need of multi-perspective and longitudinal approaches that include the perceived roles in a specific cultural and social settings, the present study aimed to understand how Portuguese people who have experienced a stroke and their carers adapt to life after stroke over time. This study also aimed to understand how the triad participants (person with stroke, carer and health professional) perceive each role during the rehabilitation and adaptation processes, the interrelations within the triad over time, as well as how health professionals may support their transition to home and adaptation to a changed life after stroke.

\section{Material and Methods}

A multi-perspective, prospective qualitative approach using in-depth semi-structured interviews was chosen to meet the aims of the study. By adopting a qualitative approach, this research allowed an in-depth understanding of the impact of stroke on the everyday life of both people with stroke and carers. In accordance with the interpretivist paradigm, committed to an emic viewpoint and idiographic position (32), the ontological and epistemological standpoints of the study were based on the understanding of illness experience as subjective feelings, personal and socially constructed meanings using a relativist and constructionist lens. Interviews were carried out at two time points. Firstly, interviews were conducted one month after discharge from hospital as an inpatient or from convalescence unit/ inpatient rehabilitation. This transition to home is characterised as being a period of changes and uncertainties. It is suggested that it is at home that both the person with stroke and carer really start to understand the changes and full consequences of stroke $(5,7)$. For that reason, both interviews took place one and six months after discharge from an inpatient setting, following their changing and developing strategies for adapting to life after stroke. 
Topic guides were based on the findings of a metasynthesis of qualitative research undertaken previously by the authors about the people with stroke and carers' perspectives throughout the first year. These interview's guides were piloted with four Portuguese people with stroke, four carers and two health professionals, with the final main topics adapted for people with stroke, carers and health professionals (see topic guide for each group in appendix 1).

\section{Study settings and sample}

The study took place in the region of Lisbon, Portugal and participants were recruited from health institutions selected according to the nature of care provided, including institutions from the National Network of Integrated Care and private rehabilitation institutions. A purposive sample of participants was selected to optimise the diversity and range of characteristics, such as moderate or severe disability (according to the Barthel Index obtained from records), age range, gender and discharge from hospital, convalescent or rehabilitation unit, with a pre-set sampling matrix to ensure a systematic selection. A list of potential participants was provided by a team member responsible for the patient's discharge plan, who obtained verbal consent to allow the researcher's initial contact of eligible participants.

Each triad included the person with stroke, a carer and a health professional involved in the person's rehabilitation. For people with stroke, the following inclusion criteria were used: 1) diagnosis of stroke from clinical observation or brain imaging; 2) undergoing outpatient stroke rehabilitation or had received rehabilitation services for at least five sessions, to be able to talk about the rehabilitation process; and 3) discharged from hospital or rehabilitation unit during the last month, to be able to talk about the process of transition to home and adaptation to life after stroke. Participants were 
excluded if they did not have Portuguese nationality, due to the cultural nature of the study. Since people with communication problems face particular challenges in family, social and rehabilitation contexts, but are commonly excluded from qualitative studies, they were included in this study, representing over a third of all participants. A meeting with these potential participants' speech and language therapist was required and, according to the level of speech intelligibility, recommendations were given to inform the best way to undertake the interview. Those recommendations were based on words understood and comprehensibility, that is, the ability to understand communication which occurs through speech, gestures, facial expressions, writing, drawing, picture pointing and other augmentative and alternative means. Strategies to promote the involvement of the person were used by the researcher with advice and support of the speech therapist, which were selected in concordance with the compensatory strategies commonly used by the participant. During the interview, the researcher took care to modify the language and verbally comment on the participants' non-verbal gestures when they occurred to ensure the meaning was appropriately understood.

Carers, defined as the person who was supporting the person with stroke at home, without payment for that service, were included if: 1) they took care of the participants, and 2) participated or attended at least one rehabilitation session (33). These criteria were considered to ensure that participants were able to talk about their role as carers and during the rehabilitation process, about the impact of transition to home and adaptation to life after stroke. For the same reason presented for people with stroke, carers were excluded if they did not have Portuguese nationality.

Health professionals were included if they worked with the patient in the rehabilitation process for a minimum of five sessions to be able to talk about the person with stroke's needs, progress, expectations, rehabilitation goals and adaptation process, 
as well as about their role helping service-users adapt to life changes after stroke.

A stepwise approach was used, starting with recruiting the person with stroke; followed by the carer and health professional. People with stroke or carers themselves identified the main carer. If more than one carer was referred and both wanted to participate, an invitation for a joint interview was offered. The main health professional was identified by the person with stroke or the carer before each time point interview. All participants had to be 18 years old or over and able to provide informed consent.

Ethical approval was sought and obtained from local research ethics committees and from the National Commission of Data Protection (N.15727). Careful planning in building consistent and sustained researcher-participant relationships were considered to avoid dropouts (34). Confidentiality and anonymity of the participants was guaranteed. All data that could lead to a possible identification were kept confidential.

\section{Data collection}

Eligible participants were invited to take part before inpatient discharge. A first meeting with the researcher was carried out in order to explain the aims and procedures of the research. By contacting potential participants before discharge from an inpatient setting allowed sufficient time for information, consideration and consent to be given. Following discharge, the researcher contacted study volunteers by phone to schedule a second meeting. After obtaining their written consent, a convenient date, place and time for interview was scheduled with participants. The setting for interviews was chosen according to the participants' preferences and convenience. Interviews mainly took place at the participants' home, work and in the hospital/service, selecting an isolated and quiet room in order to avoid interruptions and minimise the risk of being overheard. During the interview, the Portuguese researcher $(\mathrm{CP})$ reminded participants that they were under no obligation to take part and short breaks were planned if the participant was finding it 
difficult to concentrate or showing signs of fatigue. Separate interviews were initially planned to allow an exploration of individual coping styles. Joint interviews were avoided where possible in order to protect participants' privacy and minimise responses perceived as acceptable to the partner $(35,36)$. However, when preferred by participants, interviews were conducted together. Additionally, in interviews carried out with health professionals, efforts were made to minimise the risk of omissions due to a shared professional understanding and/ or the feeling of being assessed in their clinical knowledge (37). These efforts were made due to the background of the interviewer, who was a physiotherapist and researcher in the field of stroke. In order to put participants at ease, the researcher emphasised several times that there were no right or wrong answers. Moreover, additional prompts were planned to ensure clarity through an explicit response. Interviews lasted between 25-143 minutes and were audio recorded. Additional notes were taken by the researcher $(\mathrm{CP})$ during interviews particularly in interviews with people with communication problems (e.g non-verbal communication used). In addition, after each interview notes about the interviewing process were written in a reflexive diary of the researcher, which was used during the analysis process as a tool to increase the level of interpretation.

A total of ten eligible participants with stroke were initially invited by the coordinator of the rehabilitation service or a team member responsible for the patient's discharge plan. Two potential participants who had had a stroke declined to participate, declaring no interest or wish to talk about their illness.

Twenty-four participants were included. Eight were people with stroke, ten were carers (in two triads two carers participated, with both the wife and daughter interviewed together) and six were health professionals. Details about the characteristics of the participants are provided in tables 1 to 4 . Six of the participants with stroke were male; 
seven had a first stroke, all were married and were living at home. The time between stroke onset and the first interview varied due to the time spent in acute care and in a rehabilitation unit (table 2). Carers were on average eight years younger than people with stroke; eight were female, living with the person with stroke and had no previous experience of caring (table 3). Health professionals were all female and included four physiotherapists, one occupational therapist and one speech and language therapist (table 4). At point two, six months later, one family (triad 8) dropped out due to personal reasons unrelated to the study.

INSERT TABLE 1 HERE

INSERT TABLE 2 HERE

INSERT TABLE 3 HERE

INSERT TABLE 4 HERE

\section{Data analysis}

Multiple and complementary methods of analysis within the same data set were used to look both cross-sectionally and longitudinally $(34,38,39)$. An inductive thematic and narrative strategies were used. All individual interviews were transcribed verbatim immediately by $\mathrm{CP}$, coded separately and then analysed as: 1) a grouped "people with stroke set", "carers set" and "health professionals set", 2) serial interviews for each participant, and 3) integrated interview triad sets, that is, across triads and time points.

Initial analysis took place alongside continuing data generation through subsequent interviews (34), and the analysis process was iterative, allowing emerging themes to be further explored in later interviews. Thematic analysis enabled a flexibility required to identify general themes, whilst retaining individual contributions of participants from the three groups' sets (40). Each transcript was coded line by line, firstly 
from the interview of the person with stroke of the triad 1, with further codes deriving from data sequentially from other people with stroke's first interviews. These initial steps of coding interviews from the group set "people with stroke" were followed by the development of sub-themes and themes. The same steps were conducted within the other groups: "carers set" and "health professionals set", followed by the second interviews for all group sets, providing an initial indication of differences over time and divergence of perspectives.

The longitudinal approach involved analysis of individual interviews and comparison with earlier interview to determine how coping strategies changed over time. The focus was not on snapshots across time but on exploring processes and changes, looking both backwards and forwards in time $(38,39)$ using a narrative strategy $(41)$. This approach helped to understand how individual's thoughts and challenges had changed and shaped through time and interpret their explanations of changes occurring during their adaptation. This process was guided by framing questions (42) in order to help engaging in deeper levels of analysis and interpretation. Exploring longitudinal trends in the data involved a thematic horizontal analysis, which was enriched by a narrative vertical analysis, that is, a temporal analysis of serial interviews for each participant, considered as a longitudinal single unit (38).

In order to analyse multi-perspective data as "integrated interview triad" sets, including the person with stroke, the carer and health professional of each triad, a matrix linking cases to the coding frame was created, which helped maximise the strengths of the triad approach (35). Analysis of each triad gave emphasis to comparing and contrasting across differences within participants. Linking perspectives and highlighting differences between participants within the triad were explored and justified. The transcripts of triad 1 were translated to English and analysed initially by $\mathrm{CP}$ and separately 
crosschecked by FJ and NG (British researchers). The others were analysed only by CP due to the original language of interviews.

\section{Methods to assure trustworthiness, rigour and credibility}

Criteria for assessing research quality were considered according to the philosophical stance of the study $(32,43)$. From an interpretivist perspective it is expected different investigators and participants may yield different versions of truth. Diverse perspectives were therefore perceived as a strategy to enrich the understanding of the complex adaptation process after stroke and encouraging a more reflexive analysis of the data; not as criteria-based validation $(44,45)$. Given the involvement of the researcher in the research process, it was important to guarantee the transparency of the processes (46). Detailed information about the methods of data collection and analysis was considered, a reflexive practice was implemented throughout the study, detailed descriptions of the context and sufficient excerpts were given in order to improve transferability $(32,47,48)$. Accordingly, reflexivity was acknowledged as important and a systematic reflexion to analyse how the researchers' experiences and contexts informed the process and outcomes of the research was undertaken (48). In addition, in order to increase the credibility of the findings, the translation of interviews from triad 1 was carried out to promote cross-checking of data between Portuguese and British researchers. After this initial analysis, the strategy used was frequent debriefing sessions between the researcher and the supervisors of the project.

Furthermore, in order to ensure contextual accuracy and maintain the cultural meaning of the participants' expressions, translated excerpts (English) were checked against recorded interviews (Portuguese) sequentially by an English teacher, a sociologist, and two others with rehabilitation expertise. When one of the members had doubts about the accuracy of the translation, they were all invited to analyse the 
translation options and decide about the best translation.

\section{Findings}

The findings from the triads' interviews represent the analysis of data from time points, exploring changes in time for each participant and within triad members. A major theme derived from data analysis: regaining control of life, represented a shift in perspective during the first six months at home with both people with stroke and carers changing perceptions about what happened and what was important. Over time this manifested in a change in their ways of managing the situation and the perceived role of health professionals in supporting them.

Four sub-themes contributed to the theme of 'regaining control of life': importance of team involvement; differences in perceived roles within the triad; differences in expectations and collaboration within the triad; and planning a different future. These sub-themes help to explain the triads' perspectives about what was valued by each participant and how they managed the new life situation and throughout the rehabilitation process. In brief, both people with stroke and carers emphasised the importance of managing the disruption in their lives together and with the support of health professionals, highlighting the importance of team involvement. The way roles were perceived within the triad appeared to be influenced by the type of collaboration, including the role of the carer within the rehabilitation team, as well as the dependency of both people with stroke and carers on health professionals. Likewise, differences in perceived roles within the triad, differences in expectations and collaboration within the triad and planning a different future appeared to explain the transition from rehabilitation goals set by health professionals to goals set by both people with stroke and carers according to dyadic plans for the future. 
As illustrated in figure 1, sub-themes illustrate the temporal process of adjustment that contributed to regaining control of life, which was apparent in all triads and across time points, with differences in perspective being analysed. Different circles in the figure represent the variety of perspectives, ways of managing and adapting to the situation, and time needed, which is explored below in each sub-theme. Identification of the participant's group is used in quotations, followed by the identification of the triad and time point of the interview (T1- one month after discharge, or T2- six months after discharge).

\section{INSERT FIGURE 1 HERE}

\section{Importance of team involvement}

The unexpected and overwhelming nature of the stroke seemed to challenge the ability of both people with stroke and carers to manage their situation and resultant changes in their lives. From the perspective of participants from across all three groups, the support from the whole rehabilitation team was an important strategy to deal with the difficulties and challenges throughout the adaptation and rehabilitation processes. Adapting was not an individual process and involved others. However, who was involved was reported differently in triads and over time. For most participants, their perception of the team, also referred to as a "family", included the person with stroke, carer(s)/close family and health professionals. Some triads highlighted the involvement of the whole family, with each member having a specific role in supporting adaptation at home. Others also emphasised the inclusion of close friends or members of the local community. In particular, the support and presence of the family carers during their adaptation process and the rehabilitation sessions were emphasised by most triad members. Their presence in the rehabilitation sessions was generally encouraged by both people with stroke and 
health professionals, and desired by the carer. In situations where carers were not allowed to attend rehabilitation sessions it was perceived as more stressful for themselves and the person with stroke. For some, the earlier rehabilitation unit phase where the person was still in hospital was described as a barrier to the recovery and had a negative impact on how they both coped. The experience of hospitalisation appeared to represent a loss of the family support, as reported in triads 1 and 2:

\begin{abstract}
"I was always expecting my wife to show up with my family. In the hospital a person feels extremely ... lonely... Being at home it helps the family, as well as it helps the patients in their recovery. We feel cared for and supported by our family... Otherwise we can feel kind of hopeless." (Person with stroke, triad 1, T1)
\end{abstract}

"They wouldn't let us see the physiotherapy that he was doing. Sometimes my daughter tried to peek through the window, but whenever they saw us, they always told us we couldn't be there. In my opinion it's wrong... we couldn't see how he was progressing and what we could do. But we were told by another patient that he wasn't collaborating, he was lazy... and we couldn't do anything..." (Carer, triad 2, T1)

However, the presence of others was not always perceived positively, resulting in differences in perspective and possible conflicts within the family. Some people with stroke and carers preferred not to be in contact with their previous social networks as a way of avoiding others' reactions and comments. For some people with stroke, even the presence of their carers in the rehabilitation sessions was avoided. In these cases, health professionals, despite believing in the importance of the carers' presence, tried to respect their decision, as described by the speech and language therapist,

\footnotetext{
"I suggested his presence (husband), but she doesn't want it. She gives me the impression that it isn't worth it, he doesn't understand. I believe she is not yet ready for this (having the presence of her husband in the session)... I also notice that he doesn't take things seriously. We can't say: 'Come on woman, spit it out'. This seems to be constant. I have to understand better how I will address these issues with her husband." (Health professional, triad 5, T1).
} 


\begin{abstract}
"My husband is... blah, blah, blah (mentioning that he talks a lot; she makes gestures showing euphoria) [I- is he very enthusiastic?] yeah, he has to.... (gesture to express 'stop') he is always: 'you have to-to do this', or 'say that'; 'But, you don't talk, why don't you talk? '. And I: 'calm down... no, no, I don't want him here' (referring to the presence of the husband in the speech therapy session)." (Person with stroke, triad 5, T1).
\end{abstract}

Although participants from across all three groups highlighted the importance of the presence of carers, when differences in opinion within triad members occurred, it appeared to be important to select carefully when to involve them.

Over time, in some triads, a shift seemed to occur in whom was maintaining involvement in the recovery process, with carers or secondary carers becoming more involved and health professionals participating less in decisions. This appeared to be related to an increase in confidence of both carers and people with stroke regarding their capabilities to manage difficulties. For instance, carers were better able to describe how they solved specific problems and, gradually, managed to find solutions together as a way of increasing the person's independence.

\footnotetext{
"I made a calendar on the computer for him with the month and some space for him to write where he was and what he was doing (...) It was me who invented this because he was always asking me what day it was. Sometimes, for him, Monday was Sunday." (Carer, triad 2, T2)
}

\title{
Differences in perceived roles within the triad
}

In both the multi-perspective and longitudinal analysis of the interviews, participants highlighted the role of people with stroke and carers in supporting each other. However, divergences were found in how health professionals perceived their role and what both people with stroke and carers valued. 
Bidirectional support, that is, the support given to each other within the dyad, helped both the person with stroke and the carer in a mutual understanding of their needs and not feeling alone. When one was emotionally down, they could support the other. Mutual tenderness, love and support were valued and reported as giving motivation for dealing with the challenges of the new life situation and the rehabilitation process. In some triads, the person with stroke explained how important it was to feel needed, maintaining previous roles and familiar interactions. When difficulties managing the changed roles were described, the mutual support was also highlighted. In those situations, a gradual adaptation of roles appeared to be important, as shown by quotes from triad 4:

\footnotetext{
"I'm always telling my children to have more patience with their father (..) It's a war at home between them." (Carer, triad 4, T1)
}

“He says that it's very hard to impose some authority (...) We're trying to help him understand that he doesn't need to quit his role. He can do it in a different way, with his wife's help." (Health professional, triad 4, T1)

\footnotetext{
"Before this...it was me who usually corrected their language mistakes. Now it's the other way around (laugh). That makes me laugh and, at the same time, makes me cry." (Person with stroke, triad 4, T1)
}

From the perspectives of both people with stroke and carers, the interest showed by the health professionals in their adaptation and the person's recovery was important. Trusting in the professionals' work and their commitment to fulfil the families' needs was important to help them becoming more proactive and motivated. Moreover, both found it helpful if the health professional was patient and sensitive to their thoughts. For some, the health professional was a person to confide in. 
"Coming here (to the speech therapy session) helps me because I talk about everything, I vent, I don't want to worry her (...) I always talked about everything with my wife, but now there are things that I really don't want to talk about. I know she can't handle it." (Person with stroke, triad 4, T1).

"Undoubtedly their (referring to health professionals) support... and their work have been tremendous, both with him (person with stroke) and with us (wife and daughter), with all the family. They give us great encouragement (...) There are those professionals whose hearts are focused on us.” (Carer- daughter, triad 1, T2)

"I believe that she (person with stroke) changed her attitude. She started to 'wake up' when she saw lots of people around her (...) professionals interested in helping her, challenging her... even making proposals and findings solutions... we were very lucky." (Carer, triad 7, T1)

However, while families described the valuable contribution of health professionals' commitment, and the subsequent influence on their engagement in rehabilitation, health professionals seemed to view their role differently. Although they emphasised the importance of trust, some appeared to focus their attention mainly on treatment outcomes and on the families' acceptance of the treatment plan.

"They trust us. We really managed to show that our treatment approach has had some results... as they realised over time that things are really working, thus they accept any suggestion we make more easily." (Health professional, triad 1, T2).

Differences in how each perceived the role of the health professional appeared to increase the risk of conflicts and creation of different agendas. The following sub-theme helps understand how their perceived role and collaboration changed over time.

\section{Differences in expectations and collaboration within the triad}

This sub-theme represents participants' perspectives about how they worked within the team. When setting goals and engaging people in the rehabilitation process, different 
health professionals seemed to approach both people with stroke and their families differently. In particular, some tried to involve both, including the family members when possible as a way to understand and adapt rehabilitation goals to their needs, as well as to find possible solutions together. Listening to gain understanding about the problems of both people with stroke and carers was considered important in the collaboration process for this. Encouraging people with stroke and carers to look positively at situations was also highlighted by all triad members as an important approach because it was believed to help them cope with what had happened and change their perceptions of loss.

On the other hand, when rehabilitation goals were mainly set by health professionals, interaction and involvement of both people with stroke and carers was perceived as important to increase the motivation in the professionals' plan. Although the patient's needs were assessed and taken into consideration in the treatment plan, both the person and carer were often not involved in the decisions about the priorities and treatment approach. For example, in triad 1, according to the physiotherapist's viewpoint, the person and carer's expectations were identified but not considered in the initial plan. However, this plan seemed to increase the anxiety of the person with stroke and his wife about the treatment. A gap between their expectations about walking and the treatment goals appeared to place restrictions on their collaboration and engagement in the rehabilitation sessions, as stated by their daughter and the physiotherapist:

"He had said to me: 'it's always the same thing, it's balance, it's the hub and that's it'. He wasn't perceiving progression. I had to explain all the time how he was and how he is for him to understand that the treatment was just fine (...) it's hard to keep him motivated." (Carer- daughter, triad 1, T2)

"The family wanted to start walking with him at home and we said: 'it's better not, he can't have a correct body alignment and that would interfere in his walking'. That would let him use compensatory strategies... and probably it would change his walking pattern." (Health professional, triad 1, T1) 
People with stroke were initially enthusiastic about following the professionals' recommendations, despite recognising difficulty managing the frustration when their needs and expectations were not accomplished. Moreover, some health professionals described how their professional leadership was perceived as important in helping to find strategies to manage difficulties. Although the importance of people with stroke and carers' initiative was highlighted, some strategies used did not promote their ability to decide on the situations over time. Instead, it seemed to promote their dependency on professional advice, as demonstrated below,

"They do what we ask here (in the clinic) and when they want to do new things they always ask us before. They never dare to do it without asking us." (Health professional, triad 1, T1)

Over time, health professionals' approach appeared to patients and carers not to change and some reported deciding to find solutions on their own. Others, not coping positively with the professionals' approach, tried to find treatment alternatives, which was also perceived by health professionals as frustrating.

"We also see and with our initiative we can also do, do it that way (according to the health professionals' recommendations) or do it another way or hmm OK, if we agree and, if in one way or another we see that it's for our good, we do it. It's how we decide." (Carer, triad 3, T2)

"It's very frustrating. A person wants the best, works to do the best and then it's not appreciated." (Health professional, triad 7, T1)

These discrepancies between participants from across all three groups about the rehabilitation goals appeared to provoke frustration and anxiety in the person with stroke and/or the carer for not meeting their perceived needs and expectations.

\footnotetext{
"She (the therapist) is adorable. The problem is that she (Person post stroke) was being punished by the way the therapist understood that she should do the exercises and walk
} 
outside (...) I think that she doesn't have to strictly follow what others say." (Carer, triad 7, T2).

Some health professionals were worried by the families' high or unrealistic expectations, which appeared to be a potential source of tension or to lead to the creation of different agendas. With time, not adapting professional approaches seemed to increase the gap between professional efforts and both people with stroke and carers' needs.

\section{Planning a different future}

With time the major goal of both people with stroke and carers moved from expecting to regain their former lives to regaining control in their new life post-stroke. Initially, both people and carers were focused on finding ways to prioritise recovery. Hoping to have their former lives back was an important source of strength and motivation. However, over time, adapting their goals and priorities or completely changing their definition of what was important helped both people with stroke and carers to be able to regain control. Thinking of new plans for their life seemed to represent a shift in assumptions from a time when thinking about future plans was avoided and a day-to-day life style was chosen to deal with the uncertainty of outcomes, to a time when both appeared to be changing their view of the future. Both realised the need to restart their lives and analyse future possibilities. Restarting planning ahead included balancing what they desired and what was possible through meaningful activities.

\footnotetext{
"We would like to have a camper van, rid myself of the house (...). Now it's more: what if we travel tomorrow?, and we go (...) we travel a lot.” (Carer, triad 7, T2)

"It' all different, all, all... totally different [I- referring to your future?] yes, yes, yes, n-new plans, with calm (gesture to express 'slowing down')." (Person with stroke,
} triad 5, T2) 
Despite recommendations from health professionals appearing to be an important element of support for families, over time the perception of their helpfulness seemed to decrease. Their guidance seemed to continue to be focused on what both the person with stroke and carers could do to optimise rehabilitation and what strategies could improve the person's capabilities and independence, which seemed to decrease in importance over time for both the person with stroke and carer. Six months after being discharged, the focus here was less on recovery and more about how to regain control of their lives. In this sense, the health professionals' advice was not always perceived as helpful or meaningful to them. Their needs and priorities now seemed often to be different from health professionals' views:

\footnotetext{
"In the next phase we'll have to analyse with the family what could be the solutions. I know that this patient used to drive." (Health professional, triad 1, T2)

"They will have to continue living (....) I'm trying to give them their own life. Now he says he wants to try the computer. He never used a computer in his life (laughs). It's picking up these little things they tell me to take satisfaction from that." (Carerdaughter, triad 1, T2)
}

"The therapist wants him to go there, to the shop. He used to enjoy being in the shop serving the public, but now she wants him to pack things up and transport bottles as a way of moving and he doesn't want to." (Carer- daughter, triad 2, T1)

With time people with stroke and carers appeared to expect to assume control over the recovery process and their lives. Taking decisions was not stressful anymore, instead it was desired. Managing and learning how to live with the consequences of the stroke, as well as maintaining optimism about the future, even about a different future from what was previously expected, seemed to represent a challenge, as well as a goal to both people with stroke and carers. Discussing it within the families helped them to find new meaningful activities and strategies. 


\section{Discussion}

By undertaking a multi-perspective and longitudinal design to explore the adaptation process over time, this study brings a new perspective about the interrelations within the family and new insights about professionals' approach in relation to expectations and needs of both the people with stroke and carers.

This study demonstrated that mutuality in support had an important role within a Portuguese context in managing the situation after stroke. For some participants its importance was recognised even during their stay in the rehabilitation unit. The hospitalisation increased the feeling of isolation and loss of their family support, which may be also be highlighted by the considerable distance from home. These findings could reflect geographical and admission criteria difficulties within the National Network of Integrated Care (49). Despite the improvement of resources in recent years, the number and location of units in Portugal are still limited and services have been much confined to inpatient-based care $(50,51)$. A closer coordination between the acute and community, non-acute sector is required in Portugal and the implementation of an early discharge model, articulating acute and long-term care services, is recommended (52). According to the findings here, a community-based rehabilitation may be preferred for some people with stroke and their families. It will also represent an opportunity for health professionals to develop a broader and deeper understanding of their needs, adopting a collaborative approach within the triad.

By analysing the different perspectives longitudinally, this study has provided insights into the need to tailor support, showing that not every kind of support is useful. Moreover, not all significant others are able to provide the support needed. The complexity and challenges of the family involvement over time and across different dyads 
and triads was recognised by most of the health professionals. When conflicts were evident within the family or differences were reported between the needs of the person and the carer, health professionals reported difficulty in managing it, opting to focus on the person with stroke's needs. According to these findings, community-based rehabilitation may promote a more relational approach helping both people with stroke and carers in managing the situation and supporting each other. Also, decision-making seemed to occur mainly without the involvement of people with stroke, nor their carers. However, in this study, as in other studies, the carers' participation was emphasised in order to regain control of both lives as a couple/ family, planning and establishing routines $(7,53)$.

Furthermore, although health professionals tended to highlight their patientcentred values, most described how their professional expertise and leadership was important to help families in finding solutions. Difficulties seem to exist in achieving a balance between encouraging people to take control and guiding their decisions throughout the rehabilitation process, and not perpetuating a power imbalance $(18,54)$. Previous studies reported that for some people with stroke the health professionals' paternalistic role was important (55); others instead complained of paternalistic approaches $(55,56)$. Whatever the preference of the person with stroke, it appears that continued consultation about their desires about rehabilitation, priorities and goals is important $(12,57,58)$.

The divergence in priorities and rehabilitation goals that emerged from the findings may be explained by the differences in perspective. The perspective of health professionals tended to be mainly biomedical, while the perspective of the person who has suffered a stroke and carer included biomedical, social and psychological needs. These differences impact goal-setting and treatment expectations $(19,54,57)$. A possible 
reason for this divergence was the incongruence within the triad concerning hopes and expectations about recovery. Health professionals were worried about unrealistic expectations and hopes from both the people with stroke and carers. However, the person with stroke and carer were sometimes confused about the treatment plan and its relevance for fulfilling their needs, expectations and goals. Similar findings have been reported in other studies $(25,59,60)$ and systematic reviews $(57,58,61)$, emphasising it as a potential source of tension and leading to the creation of different agendas. Setting goals appeared to work well when both the person with stroke and health professionals shared the same perception of goals (20). When there was a difference, the goals of people with stroke were often seen as unrealistic, creating a major problem in the therapeutic relationship (25). Health professionals may avoid talking about prognosis in order to minimise the risk of breaking people's and carer's motivation and engagement. However, the literature suggests that a lack of information provision may also contribute to the mismatch between them (57).

By collecting data longitudinally, findings also emphasised that, over time, both people with stroke and carers started questioning themselves about their expectations in resuming their previous lives. By changing expectations and priorities over the rehabilitation period, they did not see that as "giving up", as shown by others (59), instead some saw it as an opportunity for a life transformation. This shift in perspective may be explained by a gradual assimilation about what happened, with information tailored to their needs $(6,62)$ and justified by a need for finding new meanings and creating a balance between what was desired and what was possible. In a systematic review undertaken to understand hope as described by people with stroke (61), stroke was a catalyst for developing new hopes for their futures. Some participants from this study, both people with stroke and carers seemed to perceive it similarly by describing it as a process of 
evaluating their hopes and modifying them to be realistic. This sense of transformation is characterised by a process of learning the rules in a new world, as defended by Parkes (63), highlighted by Ellis-Hills et al. (64) and Frank (65), which was found in this study to be important not only for people with stroke, but also for carers as a process of making sense of their common goals and of their world as a couple and family.

These findings reveal that gaining a dyadic perspective, health professionals may be able to better understand people with stroke' and carers' needs in their specific contexts (26), which can help them find effective ways of supporting them. This is particularly relevant in the area of stroke rehabilitation due to its impact upon different family members. By adopting a relational approach, health professionals can assist with how problems are perceived within the family over time. For this, health professionals may need to develop a broader understanding of the needs of both people with stroke and carers, family interactions and strategies used to inform their professional practice.

A gradual increase of an active engagement of both people with stroke and carers in the process should be promoted. It is crucial to understand the stage at which enabling individuals to take greater control may optimise recovery.

\section{Strengths, limitations, application and future research}

Despite the research that has been undertaken into people with stroke, carers and caring in other contexts, this study offers new insights. By undertaking a multi-perspective study involving a triad, that is, including the person with stroke, carer and health professional, this study contributed to a deeper understanding about the experiences, perceived roles and collaboration between all parties involved within the recovery and adaptation processes.

By undertaking a longitudinal design, this study also provides a deeper 
understanding of the importance of time for both people with stroke and carers to find their own way of managing their new life situation. Building on these longitudinal and multi-perspective findings, the study makes a number of further contributions to professionals' approach in relation to expectations and hopes of both the people with stroke and carers. From a rehabilitation perspective, a central question related to the common gap between perspectives is how can people with stroke and their families be supported in their efforts to construct a helpful illness trajectory projection and develop meaningful and satisfying lives after stroke. These are important challenges in moving rehabilitation away from the predominant functional and paternalistic approach $(25,64,66)$.

There are obvious limitations with generalisability or transferability of the study findings to a broader context. The research was undertaken in the context of transition to home, during six months, in a Portuguese context. Attempts were made to give the reader the possibility of considering its transferability to other Portuguese and international contexts. However, regional and cultural differences should be taken in consideration.

Considering the level of disability of the study participants, findings may have practical implications to carers and people with mild and moderate stroke, as well as to people with communication difficulties. Transferability to other conditions may be considered to participants with similar clinical and social characteristics. It would be important to consider the onset and impact of the clinical condition. These study findings may be generalised to conditions with sudden, unexpected and life-altering event, which represent a life change to both the person and those close to them and with unpredictable outcomes, such as traumatic brain injuries.

Due to the use of different languages during this study, obstacles to the analysis within the team were found with translations to English being undertaken for some 
participants' interviews. However, the analysis was not fully crosschecked by the research team due to the existence of data in Portuguese, with no resources to translate it all to English. It was also considered important to ensure the contextual accuracy and cultural meaning during translations and analysis, which would be only obtained by bilingual people.

With the limited longitudinal timeframe of six months after discharge, some issues may not have been identified and further interviews over a longer follow-up period would enrich the understanding of the complex adaptation process over time. Further studies are required to increase the timeline studied in order to understand how the dyadic relationships and support within the family change and how health professionals may support them in a community-based approach over time. Considering these first findings, further research should explore and evaluate the effects of using a dyadic perspective, that is, including both the person with stroke and carer(s) in setting shared goals. It may be important to explore the strategies that may better work to promote an effective collaboration in setting goals over the rehabilitation and adaptation post-stroke.

\section{Funding}

Funding was obtained from PROTEC - Programa de Apoio à Formação Avançada de Docentes do Ensino Superior Politécnico (literally "Programme to Support the Advanced Studies of Higher Education Teachers"), supported by the Portuguese Government Directorate of Higher Education and the Polytechnic Institute of Setubal (SFRH/PROTEC/67867/2010).

\section{Acknowledgements}

We acknowledge the participants for their contribution to this study. We also acknowledge the contribution of António Manuel Marques, Eduardo Brazete Cruz, 
Gabriela Colaço and Sarah Pearson with excerpt translations from the Portuguese recorded interviews.

\section{Declaration of conflicting interest}

The authors declare that there is no conflict of interest.

\section{References}

1. Feigin VL, Krishnamurthi R V., Parmar P, Norrving B, Mensah GA, Bennett DA, et al. Update on the global burden of ischemic and hemorrhagic stroke in 19902013: The GBD 2013 study. Neuroepidemiology. 2015;45(3):161-76.

2. Townsend N, Nichols M, Scarborough P, Rayner M. Cardiovascular disease in Europe - Epidemiological update 2015. Eur Heart J. 2015;36(40):2696-705.

3. Adamson J, Beswick A, Ebrahim S. Is stroke the most common cause of disability? J Stroke Cerebrovasc Dis. 2004;13(4):171-7.

4. Burton C. Living with stroke: a phenomenological study. J Adv Nurs. 2000 Aug;32(2):301-9.

5. Carlsson GE, Möller A, Blomstrand C. Managing an everyday life of uncertaintya qualitative study of coping in persons with mild stroke. Disabil Rehabil. 2009 Jan;31(10):773-82.

6. Ellis-Hill C, Robison J, Wiles R, McPherson K, Hyndman D, Ashburn a. Going home to get on with life: patients and carers experiences of being discharged from hospital following a stroke. Disabil Rehabil. 2009; 31(2):61-72.

7. Greenwood N, Mackenzie A, Wilson N, Cloud G. Managing uncertainty in life after stroke: A qualitative study of the experiences of established and new informal carers in the first 3 months after discharge. Int J Nurs Stud. 2009;46(8):1122-33.

8. Taule T, Råheim M. Life changed existentially: a qualitative study of experiences at 6-8 months after mild stroke. Disabil Rehabil. 2014;36(25):2107-19.

9. Banks P, Pearson C. Parallel lives: younger stroke survivors and their partners coping with crisis. Sex Relatsh Ther. 2004;19(4):413-29.

10. Jongbloed L. Adaptation to a stroke: the experience of one couple. Am J Occup Ther Off Publ Am Occup Ther Assoc. 1994;48(11):1006-13.

11. Close H, Procter S. Coping strategies used by hospitalized stroke patients: implications for continuity and management of care. J Adv Nurs. 1999;29(1):13844.

12. Theadom A, Rutherford S, Kent B, McPherson K. The process of adjustment over time following stroke: A longitudinal qualitative study. Neuropsychol Rehabil. 2018;2011:1-11.

13. Ostwald SK, Bernal MP, Cron SG, Godwin KM. Stress experienced by stroke 
survivors and spousal caregivers during the first year after discharge from inpatient rehabilitation. Top Stroke Rehabil. 2009;16(2):93-104.

14. Pringle J, Drummond JS, McLafferty E. Revisioning, reconnecting and revisiting: The psychosocial transition of returning home from hospital following a stroke. Disabil Rehabil. 2013;35(23):1991-9.

15. Ekstam L, Tham K, Borell L. Couples' approaches to changes in everyday life during the first year after stroke. Scand J Occup Ther. 2011;18(1):49-58.

16. Wohlin Wottrich A, Stenström CH, Engardt M, Tham K, von Koch L. Characteristics of physiotherapy sessions from the patient's and therapist's perspective. Disabil Rehabil. 2004;26(20):1198-205.

17. Reunanen MAT, Talvitie U, Järvikoski A, Pyöriä O, Härkäpää K. Client's role and participation in stroke physiotherapy encounters: an observational study. Eur J Physiother. 2016;18(4):210-7.

18. Talvitie U, Reunanen M. Interaction between Physiotherapists and Patients in Stroke Treatment. Physiotherapy. 2002 Feb;88(2):77-88.

19. Bendz M. The first year of rehabilitation after a stroke - from two perspectives. Scand J Caring Sci. 2003 Sep;17(3):215-22.

20. Levack WMM, Dean SG, Siegert RJ, McPherson KM. Navigating patient-centered goal setting in inpatient stroke rehabilitation: How clinicians control the process to meet perceived professional responsibilities. Patient Educ Couns. 2011;85(2):20613.

21. Ward CD. Is patient-centred care a good thing? Clin Rehabil. 2012;26(1):3-9.

22. Jönsson AC, Lindgren I, Hallström B, Norrving B, Lindgren A. Determinants of quality of life in stroke survivors and their informal caregivers. Stroke. 2005;36(4):803-8.

23. Ekstam L, Johansson U, Guidetti S, Eriksson G, Ytterberg C. The combined perceptions of people with stroke and their carers regarding rehabilitation needs 1 year after stroke: A mixed methods study. BMJ Open. 2015;5(2).

24. King RB, Shade-Zeldow Y, Carlson CE, Feldman JL, Philip M. Adaptation to stroke: a longitudinal study of depressive symptoms, physical health, and coping process. Top Stroke Rehabil. 2002 Jan;9(1):46-66.

25. Alaszewski A, Alaszewski H, Potter J. The bereavement model, stroke and rehabilitation: a critical analysis of the use of a psychological model in professional practice. Disabil Rehabil. 2004 Sep 16;26(18):1067-78.

26. OECD. OECD Reviews of Health Care Quality: Portugal 2015: Raising Standards. Paris: OECD Publishing; 2015.

27. DGS. Programa Nacional para as Doenças Cérebro-Cardiovasculares 2017 [National Programme for Cardiovascular Diseases]. Lisboa; 2017 [in Portuguese].

28. Fonseca T, Gorjão Clara J. Unidades de Acidentes Vasculares Cerebrais [Stroke Units: The First-Year Results of Pulido Valente Hospital Stroke Unit]. Rev Port Cardiol. 2004;23(10):1227-1241 [in Portuguese].

29. Moutinho M, Magalhães R, Correia M, Silva C. Avaliação da Via Verde do Acidente Vascular Cerebral no Norte de Portugal: Caracterização e Prognóstico 
dos Utilizadores [A Community-Based Study of Stroke Code Users in Northern Portugal]. 2013;26(2):113-122 [in Portuguese].

30. Pereira HR, Rebelo Botelho MA. Sudden informal caregivers: The lived experience of informal caregivers after an unexpected event. J Clin Nurs. 2011;20(17-18):2448-57.

31. Calheiros J. Chronic disease and family coping: a study in urban Portugal. The University of Connecticut; 1986.

32. Guba E, Lincoln Y. Paradigmatic controversies, contradictions and emerging confluences. In: Denzin N, Lincoln Y, editors. The Sage Handbook of Qualitative Research. Thousand Oaks: Sage Publications; 2005.

33. Lopes M, Mendes F, Escoval A, Agostinho M, Vieira C, Vieira I, et al. Plano Nacional de Saúde 2011-2016- Cuidados Continuados Integrados em Portugalanalisando o presente, perspectivando o futuro [National Health Plan 2011-2016 Integrated Care in Portugal- analysing the present, foreseeing the future]. Évora; 2010 [in Portuguese].

34. Murray SA, Kendall M, Carduff E, Worth A, Harris FM, Lloyd A, et al. Use of serial qualitative interviews to understand patients' evolving experiences and needs. BMJ. 2009;339(7727):958-60.

35. Kendall M, Murray SA, Carduff E, Worth A, Harris F, Lloyd A, et al. Use of multiperspective qualitative interviews to understand patients' and carers' beliefs, experiences, and needs. BMJ. 2010;340(7739):196.

36. Sakellariou D, Boniface G, Brown P. Using joint interviews in a narrative-based study on illness experiences. Qual Health Res. 2013;23(11):1563-70.

37. Coar L, Sim J. Interviewing one's peers: Methodological issues in a study of health professionals. Scand J Prim Health Care. 2006;24(4):251-6.

38. Calman L, Brunton L, Molassiotis A. Developing longitudinal qualitative designs: lessons learned and recommendations for health services research. BMC Med Res Methodol. 2013 Jan;13:14.

39. Holland J. Issues in Qualitative Longitudinal Research. London; 2007.

40. Braun V, Clarke V. Using thematic analysis in psychology. Qual Res Psychol. 2006 Jan;3(2):77-101.

41. Chase S. Narrative inquiry: Multiple Lenses, Approaches, Voices. In: Denzin N, Lincoln S, editors. The Sage Handbook of Qualitative Research. Thousand Oaks: Sage Publications; 2005. p. 651-79.

42. Saldana J. Longitudinal Qualitative Research- analysing change trough time. Walnut Creek: Alta Mira Press; 2003.

43. Slaughter S, Dean Y, Knight H, Nour V, Shenfield DG, Sherwood E. The Inevitable Pull of the River's Current: Interpretations Derived From a Single Text Using Multiple Research Traditions. Qual Health Res. 2007;17(4):548-61.

44. Malterud K. Qualitative research: standards, challenges, and guidelines. Lancet. 2001 Aug 11;358(9280):483-8.

45. Mays N, Pope C. Assessing quality in qualitative research. Qual Res. 2000;320(January). 
46. Popay J, Rogers A, Williams G. Rationale and Standards for the Systematic Review of Qualitative Literature in Health Services Research. Qual Health Res. 1998;8(3):341-51.

47. Denzin N, Lincoln Y. The Discipline and Practice of Qualitative Research. In: Denzin N, Lincoln Y, editors. The Sage Handbook of Qualitative Research. Thousand Oaks: Sage Publications; 2005. p. 1-32.

48. Etherington K. Becoming a Reflexive Researcher: using ourselves in research. London: Jessica Kingsley Publishers; 2004.

49. Entidade Reguladora da Saúde. Acesso, Qualidade e Concorrência nos Cuidados Continuados e Paliativos [Access, Quality and Competition in Integrated Care]. Porto; 2015 [in Portuguese].

50. Simões J, Augusto GF, Fronteira I, Hernández-Quevedo C. Health Systems in Transition Portugal. Heal Syst Tran. 2017;19(2):1-184.

51. Santana S, Szczygiel N, Redondo P. Integration of care systems in Portugal: Anatomy of recent reforms. Int J Integr Care. 2014;14(JUL/SEP):1-10.

52. OECD. OECD Reviews of Health Care Quality: Portugal. OCDE Publishing; 2015. 1-34 p.

53. Greenwood N, MacKenzie A, Cloud G, Wilson N. Loss of autonomy, control and independence when caring: A qualitative study of informal carers of stroke survivors in the first three months after discharge. Disabil Rehabil. 2010;32(2):125-33.

54. Jones F, Mandy A, Partridge C. Who's in control after a stroke? Do we disempower our patients? Physiother Res Int. 2000;5(4):249-53.

55. Bendz M. Rules of relevance after a stroke. Soc Sci Med. 2000;51(5):713-23.

56. Jones F. An individual approach to stroke recovery. Physiother Res Int. 2004 Jan;9(3):147-8.

57. Gallacher K, Morrison D, Jani B, Macdonald S, May CR, Montori VM, et al. Uncovering treatment burden as a key concept for stroke care: a systematic review of qualitative research. PLoS Med. 2013 Jun;10(6):e1001473.

58. Peoples H, Satink T, Steultjens E. Stroke survivors' experiences of rehabilitation: A systematic review of qualitative studies Stroke survivors' experiences of rehabilitation: A systematic review of qualitative studies. Scand J Occup Ther. 2011;18(18):163-71.

59. Daniels R, Winding K, Borell L. Experiences of Occupational Therapists in Stroke Rehabilitation: Dilemmas of Some Occupational Therapists in Inpatient Stroke Rehabilitation. Scand J Occup Ther. 2002;9(4):167-75.

60. Jones F, Mandy A, Partridge C. Reasons for recovery after stroke: A perspective based on personal experience. Disabil Rehabil. 2008;30(7):507-16.

61. Bright F, Kayes N, McCann C, McPherson K. Understanding Hope After Stroke: A Systematic Review of the Literature Using Concept Analysis. Top Stroke Rehabil. 2011;18:490-508.

62. Ghazzawi A, Kuziemsky C, O’Sullivan T. Using a complex adaptive system lens to understand family caregiving experiences navigating the stroke rehabilitation 
system Organization, structure and delivery of healthcare. BMC Health Serv Res. 2016;16(1):1-10.

63. Murray Parkes C. Psycho-social transitions: A field for study. Soc Sci Med. 1971;5(2):101-15.

64. Ellis-Hill C, Payne S, Ward C. Using stroke to explore the life thread model: an alternative approach to understanding rehabilitation following an acquired disability. Disabil Rehabil. 2008 Jan;30(2):150-9.

65. Frank A. The Wounded Storyteller: Body, Illness and Ethics. 2nd ed. London: The University of Chicago Press; 2013.

66. Gustafsson L, McLaughlin K. An exploration of clients' goals during inpatient and outpatient stroke rehabilitation. Int J Ther Rehabil. 2013;16(6):324-30. 
Appendix 1: Topic guide for each participants group.

\begin{tabular}{|c|c|c|c|}
\hline Questions & People with stroke & Carers & Health professionals \\
\hline $\begin{array}{l}\text { Topic 1: } \\
\text { introductory } \\
\text { questions }\end{array}$ & $\begin{array}{l}\text { What happened on the } \\
\text { day you had your } \\
\text { stroke? Can you } \\
\text { describe what was most } \\
\text { meaningful for you? }\end{array}$ & $\begin{array}{l}\text { What happened on the } \\
\text { day your relative }(e . g . \\
\text { husband/wife/ father }) \\
\text { had a stroke? Can you } \\
\text { describe what was most } \\
\text { meaningful for you and } \\
\text { him/her? }\end{array}$ & $\begin{array}{l}\text { In your perspective, how have the } \\
\text { person and family been dealing } \\
\text { with what happened? }\end{array}$ \\
\hline \multirow[t]{2}{*}{$\begin{array}{l}\text { Topic 2: } \\
\text { Adapting } \\
\text { after stroke }\end{array}$} & $\begin{array}{l}\text { How have you been } \\
\text { dealing with the fact that } \\
\text { you had suffered a } \\
\text { stroke? }\end{array}$ & \multirow{2}{*}{$\begin{array}{l}\text { How do you think your } \\
\text { relative is dealing with } \\
\text { what happened? } \\
\text { How is life for both now? } \\
\text { What are your } \\
\text { expectations in future? }\end{array}$} & $\begin{array}{l}\text { In your perspective, what have } \\
\text { been the position and actions of } \\
\text { the stroke patient and carer during } \\
\text { rehabilitation? }\end{array}$ \\
\hline & $\begin{array}{l}\text { How is life for you now? } \\
\text { What are your } \\
\text { expectations in future? }\end{array}$ & & $\begin{array}{l}\text { Do you think that their thoughts } \\
\text { and actions are helpful for the } \\
\text { recovery? Why? }\end{array}$ \\
\hline \multirow{5}{*}{$\begin{array}{l}\text { Topic 3: } \\
\text { Coping with } \\
\text { rehabilitation } \\
\text { challenges }\end{array}$} & $\begin{array}{l}\text { What was/ tell me about } \\
\text { your rehabilitation }\end{array}$ & \multirow{5}{*}{$\begin{array}{l}\text { Since your relative started } \\
\text { rehabilitation, what do } \\
\text { you think has been your } \\
\text { role in recovery? Why? } \\
\text { Why did you come to the } \\
\text { rehabilitation sessions? }\end{array}$} & $\begin{array}{l}\text { How do you think you can help } \\
\text { them? }\end{array}$ \\
\hline & What do you feel is your & & \multirow{2}{*}{$\begin{array}{l}\text { Are the expectations and goals of } \\
\text { the stroke survivor and carer being } \\
\text { achieved? How you work with } \\
\text { them to achieve their goals? }\end{array}$} \\
\hline & $\begin{array}{l}\text { role in your own } \\
\text { recovery? Why? }\end{array}$ & & \\
\hline & $\begin{array}{l}\text { What sort of support has } \\
\text { been helpful for you } \\
\text { during recovery? }\end{array}$ & & $\begin{array}{l}\text { What is your perceived role for a } \\
\text { better adaptation of individuals } \\
\text { after stroke and their carers? }\end{array}$ \\
\hline & $\begin{array}{l}\text { What are your } \\
\text { expectations with } \\
\text { rehabilitation? How do } \\
\text { you feel that the work } \\
\text { done in rehabilitation is } \\
\text { being/ will be important } \\
\text { for your expectations? }\end{array}$ & & \\
\hline
\end{tabular}


Table 1- Characteristics of the study populations included in the study.

\begin{tabular}{lccccc} 
& N & $\begin{array}{c}\text { Age range } \\
\text { Mean (SD) }\end{array}$ & $\begin{array}{c}\text { Age range } \\
\text { min - max }\end{array}$ & $\begin{array}{c}\text { Gender } \\
\text { female }\end{array}$ & $\begin{array}{c}\text { Ethnicity } \\
\text { white, Portuguese }\end{array}$ \\
\hline Participants (total) & 24 & $57.7(14.6)$ & $28-79$ & 16 & $\begin{array}{c}23(1 \text { Black, } \\
\text { Portuguese) }\end{array}$ \\
\hline People with Stroke & 8 & $66(12.5)$ & $43-79$ & 2 & $\begin{array}{c}7(1 \text { Black, } \\
\text { Portuguese })\end{array}$ \\
\hline Carers & 10 & $58(15.2)$ & $37-77$ & 8 & 10 \\
\hline Health Professionals & 6 & $46(10.1)$ & $28-58$ & 6 & 6 \\
\hline
\end{tabular}

Legend: N- number; SD- Standard Deviation

Table 2 - Characteristics of people with stroke.

\begin{tabular}{|c|c|c|c|c|c|c|c|}
\hline Triad & Age & $\begin{array}{l}\text { Time } \\
\text { after } \\
\text { stroke } \\
\text { (months) }\end{array}$ & $\begin{array}{l}\text { Discharge } \\
\text { from }\end{array}$ & $\begin{array}{l}\text { Professional } \\
\text { status }\end{array}$ & $\begin{array}{l}\text { Severity } \\
\text { of stroke } \\
\text { (Barthel } \\
\text { score) }\end{array}$ & $\begin{array}{c}\text { Rehabilitation } \\
\text { service }\end{array}$ & Interviews (place) \\
\hline 1 & 66 & 7 & $\begin{array}{l}\text { Rehabilitation } \\
\text { unit }\end{array}$ & $\begin{array}{l}\text { Fishmonger } \\
\text { (before stroke) }\end{array}$ & 40 & Physiotherapy & $\begin{array}{l}\mathrm{T} 1-57 \mathrm{~m} \text { (clinic) } \\
\mathrm{T} 2-1 \mathrm{~h} \text { (clinic) } \\
\text { In both interviews the } \\
\text { spouse was present }\end{array}$ \\
\hline 2 & 71 & 8 & $\begin{array}{l}\text { Rehabilitation } \\
\text { unit }\end{array}$ & $\begin{array}{l}\text { Serviceman: } \\
\text { retired }\end{array}$ & 100 & Physiotherapy & $\begin{array}{l}\mathrm{T} 1-49 \mathrm{~m} \text { (clinic) } \\
\mathrm{T} 2-30 \mathrm{~m} \text { (clinic) }\end{array}$ \\
\hline 3 & 54 & 2 & Hospital & $\begin{array}{l}\text { Civil } \\
\text { construction } \\
\text { (before stroke) }\end{array}$ & 100 & $\begin{array}{l}\text { Physiotherapy; } \\
\text { Occupational } \\
\text { therapy }\end{array}$ & $\begin{array}{l}\text { T1 - 48m (hospital) } \\
\mathrm{T} 2-54 \mathrm{~m} \text { (SCMP) }\end{array}$ \\
\hline 4 & 43 & 2 & Hospital & Unemployed & $\begin{array}{c}100 \\
\text { Apraxia } \\
\text { of } \\
\text { discourse }\end{array}$ & Speech therapy & T1 - 1h28 (hospital) \\
\hline 5 & 73 & 2 & Hospital & $\begin{array}{l}\text { Rehabilitation } \\
\text { auxiliary: retired }\end{array}$ & $\begin{array}{c}100 \\
\text { Aphasia }\end{array}$ & Speech therapy & $\begin{array}{l}\text { T1 - 1h15 (hospital) } \\
\text { T2 - 54m (hospital) }\end{array}$ \\
\hline 6 & 79 & 2 & Hospital & $\begin{array}{l}\text { work } \\
\text { distribution: } \\
\text { retired }\end{array}$ & 100 & Physiotherapy & $\begin{array}{l}\text { T1 - 1h25 (hospital) } \\
\mathrm{T} 2-23 \mathrm{~m} \text { (school) }\end{array}$ \\
\hline 7 & 63 & 8 & $\begin{array}{l}\text { Rehabilitation } \\
\text { unit }\end{array}$ & Teacher: retired & $\begin{array}{c}45 \\
\text { Aphasia }\end{array}$ & Physiotherapy & $\begin{array}{l}\text { T1 - 1h35 (home) } \\
\text { T2 - 1h43 (school) } \\
\text { Interview together }\end{array}$ \\
\hline 8 & 79 & 5 & Hospital & $\begin{array}{l}\text { Municipal work: } \\
\text { retired }\end{array}$ & $\begin{array}{c}65 \\
\text { Aphasia }\end{array}$ & -- & $\begin{array}{l}\text { T1 - 1h19 (home) } \\
\text { Interview together }\end{array}$ \\
\hline
\end{tabular}

Legend: T1- 1 month after discharge; T2- 6 months after discharge

Table 3 - Characteristics of carers.

\begin{tabular}{|c|c|c|c|c|c|c|}
\hline Triad & Age & $\begin{array}{l}\text { Relationship } \\
\text { with the } \\
\text { person with } \\
\text { stroke }\end{array}$ & Living situation & $\begin{array}{l}\text { Previous } \\
\text { experience } \\
\text { of caring }\end{array}$ & $\begin{array}{l}\text { Professional } \\
\text { status }\end{array}$ & $\begin{array}{l}\text { Interviews } \\
\text { (place) }\end{array}$ \\
\hline 1 & 64 & Spouse & $\begin{array}{l}\text { Living with the person with } \\
\text { stroke }\end{array}$ & No & $\begin{array}{l}\text { Fishmonger: } \\
\text { retired }\end{array}$ & \multirow{2}{*}{$\begin{array}{l}\mathrm{T} 1-1 \mathrm{~h} \text { (clinic) } \\
\mathrm{T} 2-1 \mathrm{~h} 5 \text { (clinic) }\end{array}$} \\
\hline 1 & 44 & Daughter & -- & No & $\begin{array}{l}\text { Teacher (physical } \\
\text { education) }\end{array}$ & \\
\hline 2 & 46 & Daughter & -- & No & Businesswoman & $\mathrm{T} 1-54 \mathrm{~m}$ (clinic) \\
\hline 3 & 51 & Spouse & $\begin{array}{l}\text { Living with the person with } \\
\text { stroke }\end{array}$ & No & $\begin{array}{l}\text { Teaching } \\
\text { assistant }\end{array}$ & $\mathrm{T} 1-29 \mathrm{~m}$ (hospital) \\
\hline
\end{tabular}




\begin{tabular}{|c|c|c|c|c|c|c|}
\hline 4 & 37 & Spouse & $\begin{array}{l}\text { Living with the person with } \\
\text { stroke and } 2 \text { sons }\end{array}$ & Yes & $\begin{array}{l}\text { Supermarket } \\
\text { worker }\end{array}$ & T1 - 29m (hospital) \\
\hline 5 & 76 & Husband & $\begin{array}{l}\text { Living with the person with } \\
\text { stroke and son }\end{array}$ & No & $\begin{array}{l}\text { Serviceman: } \\
\text { retired }\end{array}$ & $\begin{array}{l}\text { T1 }-53 \mathrm{~m} \text { (hospital) } \\
\text { T2 }-1 \mathrm{~h} 20 \text { (hospital) }\end{array}$ \\
\hline 6 & 76 & Spouse & $\begin{array}{l}\text { Living with the person with } \\
\text { stroke and daughter }\end{array}$ & Yes & Teacher: retired & \multirow[t]{2}{*}{$\begin{array}{l}\mathrm{T} 1-47 \mathrm{~m} \text { (hospital) } \\
\mathrm{T} 2-36 \mathrm{~m} \text { (school) }\end{array}$} \\
\hline 6 & 43 & Daughter & $\begin{array}{l}\text { Living with the person with } \\
\text { stroke and mother }\end{array}$ & No & Teacher & \\
\hline 7 & 64 & Husband & $\begin{array}{l}\text { Living with the person with } \\
\text { stroke }\end{array}$ & No & Teacher: retired & $\begin{array}{l}\text { T1 }-1 \text { h35 (home) } \\
\text { T2 }-1 \text { h43 (school) } \\
\text { Interview together }\end{array}$ \\
\hline 8 & 77 & Spouse & $\begin{array}{l}\text { Living with the person with } \\
\text { stroke }\end{array}$ & No & Farmer: retired & $\begin{array}{l}\text { T1 - 1h19 (home) } \\
\text { Interview together }\end{array}$ \\
\hline
\end{tabular}

Legend: T1- 1 month after discharge; T2- 6 months after discharge

Table 4 - Characteristics of health professionals.

\begin{tabular}{|c|c|c|c|c|c|}
\hline Triad & Age & Gender & Profession & Professional setting & Interviews (place) \\
\hline 1 & 48 & Female & Physiotherapist & Private clinic & $\begin{array}{l}\mathrm{T} 1-45 \mathrm{~m} \text { (clinic) } \\
\mathrm{T} 2-24 \mathrm{~m} \text { (clinic) }\end{array}$ \\
\hline 3 & 52 & Female & $\begin{array}{l}\text { Occupational } \\
\text { therapist }\end{array}$ & Hospital & $\mathrm{T} 1-32 \mathrm{~m}$ (hospital) \\
\hline 3 & 58 & Female & Physiotherapist & $\begin{array}{l}\text { Non-profit rehabilitation } \\
\text { institution for social solidarity }\end{array}$ & $\mathrm{T} 2-29 \mathrm{~m}$ (clinic) \\
\hline 4,5 and 8 & 49 & Female & $\begin{array}{l}\text { Speech and } \\
\text { language } \\
\text { therapist }\end{array}$ & Hospital & $\begin{array}{l}\text { Triad 4: } \\
\text { T1 - 57m (hospital) } \\
\text { Triad 5: } \\
\text { T1 - 40m (hospital) } \\
\text { T2 - 15m (hospital) } \\
\text { Triad 8: } \\
\text { T1 } 12 \mathrm{~m} \text { (hospital) }\end{array}$ \\
\hline 6 & 46 & Female & Physiotherapist & Hospital & $\mathrm{T} 1-16 \mathrm{~m}$ (hospital) \\
\hline 7 & 28 & Female & Physiotherapist & Private clinic & $\begin{array}{l}\mathrm{T} 1-34 \mathrm{~m} \text { (school) } \\
\mathrm{T} 2-24 \mathrm{~m} \text { (school) }\end{array}$ \\
\hline
\end{tabular}

Legend: T1- 1 month after discharge; T2- 6 months after discharge 